NASA Technical Memorandum 107278

AIAA-96-4145

\title{
Cascade Optimization Strategy for Aircraft and Air-Breathing Propulsion System Concepts
}

Surya N. Patnaik

Ohio Aerospace Institute

Cleveland, Ohio

Thomas M. Lavelle, Dale A. Hopkins, and Rula M. Coroneos

Lewis Research Center

Cleveland, Ohio

Prepared for the

Sixth Symposium on Multidisciplinary Analysis and Optimization cosponsored by AIAA, USAS, NASA, and ISSO

Bellevue, Washington, September 4-6, 1996

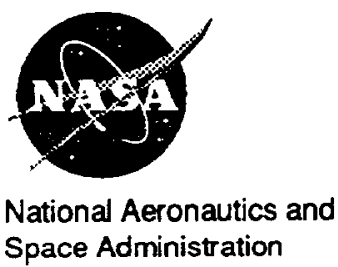




\title{
CASCADE OPTIMIZATION STRATEGY FOR AIRCRAFT AND AIR-BREATHING PROPULSION SYSTEM CONCEPTS
}

\author{
Surya N. Patnaik \\ Ohio Aerospace Institute \\ Cleveland, Ohio 44142 \\ Thomas M. Lavelle, Dale A. Hopkins, and Rula M. Coroneos \\ National Aeronautics and Space Administration \\ Lewis Research Center \\ Cleveland, Ohio 44135
}

\begin{abstract}
$\underline{\text { Abstract }}$
Design optimization for subsonic and supersonic aircraft and for air-breathing propulsion engine concepts has been accomplished by soft-coupling the Flight Optimization System (FLOPS) and the NASA Engine Performance Program analyzer (NEPP), to the NASA Lewis multidisciplinary optimization tool COMETBOARDS. Aircraft- and engine-design problems, with their associated constraints and design variables, were cast as nonlinear optimization problems with aircraft weight and engine thrust as the respective merit functions. Because of the diversity of constraint types and the overall distortion of the design space, the most reliable single optimization algorithm available in COMETBOARDS could not produce a satisfactory, feasible optimum. Some of COMETBOARDS' unique features, which include a cascade strategy, variable and constraint formulations, and scaling devised especially for difficult multidisciplinary applications, successfully optimized the performance of both aircraft and engines. The cascade method has two principal steps: In the first, the solution initiates from a user-specified design and optimizer; in the second, the optimum design obtained in the first step with some random perturbation is used to begin the next specified optimizer. The second step is repeated for a specified sequence of optimizers or until a successful solution of the problem is achieved. A successful solution should satisfy the specified convergence criteria and have several active constraints but no violated constraints. The cascade strategy available in the combined COMETBOARDS, FLOPS, and NEPP design tool converges to the same global optimum solution even when it starts from different design points. This reliable and robust design tool eliminates manual intervention in the design of aircraft and of airbreathing propulsion engines where it eases the cycle analysis procedures. The combined code is also much
\end{abstract}

easier to use, which is an added benefit. This paper describes COMETBOARDS and its cascade strategy and illustrates the capability of the combined design tool through the optimization of a subsonic aircraft and a highbypass-turbofan wave-rotor-topped engine.

\section{Introduction}

The analysis and preliminary design of subsonic and supersonic aircraft can be attempted with the Flight Optimization System computer code (FLOPS), which incorporates several different disciplines: weight, aerodynamics, engine cycle analysis, propulsion data interpolation, mission performance, takeoff and landing, noise footprint, cost, and program control. With specific input data, FLOPS can analyze as well as design a set of configuration parameters for either subsonic or supersonic aircraft. Optimization by FLOPS, however, can result in convergence difficulties because of the distortion of the multidisciplinary design space and because of the statistical and empirical equations and smoothing techniques used to analyze aircraft performance. To optimize the design of subsonic and supersonic aircraft, the FLOPS code was incorporated, as an aircraft analyzer, into the NASA Lewis design optimization computer code COMETBOARDS (Comparative Evaluation Test Bed of Optimization and Analysis Routine for the Design of Structures). This combined design tool (FLOPS analyzer and COMETBOARDS optimizer) successfully solved both subsonicand supersonic-aircraft problems.

Likewise, the air-breathing engines of subsonic and supersonic aircraft can be analyzed and designed by using the NASA Engine Performance Program (NEPP). This computer code can simulate almost any type of turbine engine configuration. NEPP can evaluate the performance of an engine over its flight envelop, with different mission points, each defined by a different Mach-number, altitude,

This paper is declared a work of the U.S. Government and is not

subject to copyright protection in the United States. 
and power-setting combination. NEPP also provides for design optimization of engine parameters at a specified mission point. However, NEPP can experience difficulties with optimization, producing infeasible suboptimal designs that require manual redesign. In an effort to eliminate the optimization deficiency of the NEPP code and improve its reliability, we combined NEPP with COMETBOARDS. This combined tool has successfully optimized a number of subsonic and supersonic engines.

The key features and unique strengths of COMETBOARDS that assisted in optimizing the aircraft and engines include the cascade optimization strategy, the constraint and design formulations, and a global scaling strategy. This paper presents an introduction to COMETBOARDS and demonstrates the capability of the combined tool by design optimization of a subsonic aircraft and a high-bypass-turbofan subsonic engine with a wave rotor.

\section{COMETBOARDS Test Bed}

The multidisciplinary design optimization test bed COMETBOARDS, which is used in the design of aircraft and air-breathing propulsion engines, has a modular organization as depicted in Fig. 1. Some key features of the test bed are multidisciplinary optimization (with separate objectives, constraints, and variables for each discipline), substructure optimization in sequential and parallel computational platforms, and state-of-the-art optimization algorithms. An analysis approximation by means of linear regression analysis and neural networks is being added. The COMETBOARDS system first formulates the design as a nonlinear mathematical programming problem, and then it solves the resulting problem. The problem can be formulated (variables, constraints, objective, etc.) by the analysis tools available in the "Analyzers" module reading specified data in the "Data files" module. A number of analysis tools (RPK_NASTRAN ${ }^{1}$ for structural analysis, NEPP $^{2}$ for airbreathing engine performance analysis, FLOPS ${ }^{3}$ for aircraft flight optimization analysis, etc.) are available in COMETBOARDS, and provision exists for the softcoupling and quick integration of new analysis tools.

The COMETBOARDS solution technique exploits several of the unique strengths that are available in its "Optimizers" module, such as a cascade optimization strategy, the formulation of design variables and constraints, and a global scaling strategy. COMETBOARDS is written in FORTRAN 77 language and currently is available on the Cray and Convex computers and the Iris and Sun workstations. Successful COMETBOARDS solutions for a number of diverse industrial problems (such as components of the Space Station, the rear divergent flap of a downstream mixing nozzle for a
High Speed Civil Transport (HSCT) engine, system optimization for subsonic and supersonic aircraft, thrust optimization for multimission HSCT mixed-turbofan engines, and optimization of a wave-rotor concept in propulsion engines) illustrate its versatility and robustness.

\section{Cascade Optimization Strategy}

COMETBOARDS can solve difficult optimization problems by using the cascade strategy depicted in Fig. 2 . The basic cascade concept is to use more than one optimizer to solve a complex problem when individual optimizers face difficulties. A COMETBOARDS user has considerable flexibility in developing a cascade strategy; selections can be made from a number of optimizers, their convergence criteria, analysis approximations, and the amount of random perturbations between optimizers. Consider, for example, a four-optimizer cascade (optimizer one followed by three other optimizers) that was used to successfully solve a subsonic aircraft problem. For such a cascade, individual convergence criteria can be specified for each optimizer. For example, a coarse stop criterion may be sufficient for the first optimizer, whereas a fine stop criterion may be necessary for the last optimizer. Likewise, an approximate analysis may suffice for the first optimizer, although an accurate analysis may be reserved for the final optimizer. The amount of pseudorandom perturbation for design variables may be specified between the optimizers at the discretion of the user. Space does not permit a description of all the different features and unique strengths of COMETBOARDS; more information can be found in Refs. 4 to 6 .

\section{Design of an Aircraft Concept}

Advanced subsonic- and supersonic-aircraft design concepts have been successfully optimized with a tool created by soft-coupling FLOPS (as the analyzer) and COMETBOARDS (as the optimizer). The FLOPS analyzer, through its control and eight discipline modules, can evaluate the performance parameters of an advanced aircraft concept and formulate its design as a nonlinear programming problem. There are options for a number of merit functions (gross takeoff weight, weight of fuel burned, range, cost, NOx emissions, etc.). Free variables for the purpose of optimization include wing area, wing sweep, wing aspect ratio, wing taper ratio, wing thickness-chord ratio, thrust or engine size, engine designpressure ratio, and turbine inlet temperature. Important behavior constraints are approach velocity, jet velocities, takeoff and landing field lengths, missed approach margins, and fuel capacity.

The multidisciplinary optimization problem posed had a distorted design space since both the design 
variables and the constraints varied over a very wide range. For example, an engine thrust design variable (which is measured in kilopounds) is immensely different from the bypass-ratio variable (which is a small number). Likewise, the landing velocity constraint (in knots) and field length limitation (in thousands of feet) differ both in magnitude and in units of measure. The difficult nature of the design problem was further compounded by the statistical and empirical equations and the smoothing techniques employed in the FLOPS analyzer. In other words, the FLOPS analyzer can be numerically unstable for some combinations of design variables, especially for a subsonic aircraft.

The most robust individual optimizer available in COMETBOARDS could not provide a satisfactory direct solution of the problem. However, by applying some of the advanced features and unique strengths of COMETBOARDS, such as the cascade strategy, state-of-the-art optimization algorithms, design variable formulation, constraint formulation, and global scaling strategy, a number of advanced aircraft design problems were successfully solved.

The cascade strategy can be illustrated by the example of a subsonic-aircraft design optimization. The fouroptimizer cascade shown in Fig. 2 successfully solved the problem. The first optimizer, which oscillated rather violently, initially produced a solution in about 30 iterations (see Fig. 2). However, the solution was infeasible and was $1380.4 \mathrm{lb}$ heavier than the true optimum. The second optimizer initiated from the first solution with a 4-percent random perturbation. As shown in Fig. 2, the algorithm converged to an infeasible solution in about 10 iterations. This solution was $598.9 \mathrm{lb}$. lighter than the previous result, but heavier than the true optimum by $781.5 \mathrm{lb}$. The third optimizer began from the second solution with a 1-percent perturbation and produced a feasible design in about 10 iterations, but it was suboptimal by $738.7 \mathrm{lb}$. Starting with a 1-percent perturbation from the previous solution, the final optimizer converged in about 25 iterations, producing a feasible and optimum solution of $199275.6 \mathrm{lb}$ for the takeoff weight of the subsonic aircraft.

The optimum design of the aircraft has been verified graphically, as shown in Fig. 3. The first graph in Fig. 3 depicts the constraints and weight function with respect to the engine-thrust and wing-area design variables. The optimum lies at the intersection of two constraints, the excess fuel and the takeoff field length. With respect to the fan-pressure and bypass ratios, the weight function reaches the minimum point without any active constraints. The other three graphs in Fig. 3 depict aircraft behavior constraints and weight function contours for three sets of design variables: overall pressure ratio and turbine inlet temperature; wing-thickness-chord ratio as a function of wing sweep; and aspect ratio versus wing sweep. At optimum, the subsonic aircraft has a minimum takeoff weight of $199275.6 \mathrm{lb}$ and has four active constraints, which are takeoff field length, excess fuel, maximum pressure ratio, and maximum turbine inlet temperature. The combined COMETBOARDS-FLOPS tool successfully solved the subsonic-aircraft design optimization problem.

\section{Design of a Wave-Rotor-Topped Engine}

Conceptually, the wave rotor replaces the burner in conventional air-breathing engines. The wave-rotor topping can lead to higher specific power in the engine or more thrust for less fuel consumption. Design optimization was carried out for a high-bypass-ratio-turbofan wave-rotorenhanced subsonic engine with four ports (the burner inlet, burner exhaust, compressor inlet, and turbine exhaust ports). The 47 mission points specified by Mach-number, altitude, and power setting combinations are depicted in Fig. 4. The engine performance analysis, and constraint and objective formulations were generated with NEPP, whereas design optimization was carried out with COMETBOARDS. To examine the benefits that accrued from the wave-rotor enhancement, we designed the engine under the assumption that most of the baseline variables and constraints were passive and that the important parameters directly associated with the wave rotor were active. The active variables considered were the rotational speed of the wave rotor and the heat added to the wave rotor. Important active constraints included the limits on maximum speeds of the compressors, a 15-percent surge margin for all compressors, and a maximum wave-rotor exit temperature. The engine thrust was selected as the merit function.

The wave-rotor-engine design became a sequence of 47 optimization subproblems (one for each mission point defined by an altitude, Mach-number, and power combination). Only by using the cascade strategy could the problem be solved successfully for the entire flight envelop. For the mission point defined by Mach number $=0.1$ and altitude $=5000 \mathrm{ft}$, the convergence of the two-optimizer cascade strategy is shown in Fig. 5. The first optimizer produced an infeasible design at $67060.87 \mathrm{lb}$ thrust in about five design iterations. The second optimizer, starting from the first solution with a small perturbation, produced a feasible optimum design with an optimum thrust of $66901.28 \mathrm{lb}$ (see Fig. 5). The optimum solution- $54743 \mathrm{lb}$ of engine thrust, $6191 \mathrm{rpm}$ for wave-rotor speed, and $109312 \mathrm{Btu} / \mathrm{sec}$ of added heat-was verified graphically in Fig. 6. In this figure, note the differences between the solutions of the individual optimizer NEPP and the combined tool. The COMETBOARDS cascade strategy produced a higher thrust than did the NEPP optimizer. Furthermore, the 
compressor speed was an active constraint in the cascade technique, but was passive for the NEPP solution. The optimum solutions for the 47 mission points obtained by using the combined tool were normalized with respect to the NEPP results and are shown in Fig. 7. This figure depicts the value-added benefit of the wave rotor in design optimization by the combined COMETBOARDSNEPP design tool. Figure 7 shows that the combined tool produced a higher thrust than the NEPP over the entire 47 mission points, with maximum increases around mission points 12,26 , and 32 . Both NEPP and COMETBOARDS-NEPP produced identical optimum thrust values for a few mission points. However, the maximum difference in thrust exceeded 5 percent for several mission points. These differences could be significant if the design points with increased thrust were used to size the engine. The combined COMETBOARDSNEPP tool successfully solved the subsonic waverotor-engine design optimization problem.

\section{Summary of Results}

The combined COMETBOARDS design tool (augmented with the analyzer FLOPS for aircraft and with NEPP for air-breathing propulsion engines) successfully solved a number of aircraft and engine design problems. The advanced features and unique strengths of COMETBOARDS made subsonic- and supersonic-aircraft design problems and engine-cycle design problems easier to solve. The cascade optimization strategy was especially helpful in generating feasible optimum solutions when an individual optimizer encountered difficulty. The cascade strategy converged to the same optimum design even when it started from different initial design points. The researchlevel software COMETBOARDS, with some enhancement and modification, can be used by the aircraft industry to design aircraft and their engines.

\section{References}

1. RPK_NASTRAN, COSMIC, University of Georgia, Athens, GA.

2. Klann, J.N.; and Snyder C.A.:, NEPP Programmers Manual. NASA TM-106575, 1994.

3. McCullers, L.A.: FLOPS: Aircraft Configuration Optimization Including Optimized Flight Profiles. NASA CP-2327, 1984.

4. Guptill, J.D. et al.: COMETBOARDS Users Manual, NASA TM-4537, 1996.

5. Patnaik, S.N. et al.: "Comparative Evaluation of Different Optimization Algorithms for Structural Design Applications," Int. Jnl. Num. Meth. Engr., Vol. 39, 1996, 1761-1774.

6. Patnaik, S.N.; Gendy A.S.; and Hopkins D.A.: "Design Optimization of Large Structural Systems With Substructuring in a Parallel Computational Environment," Comp. Systems Eng., Vol. 5, No. 4-6, 1994, 425-440. 


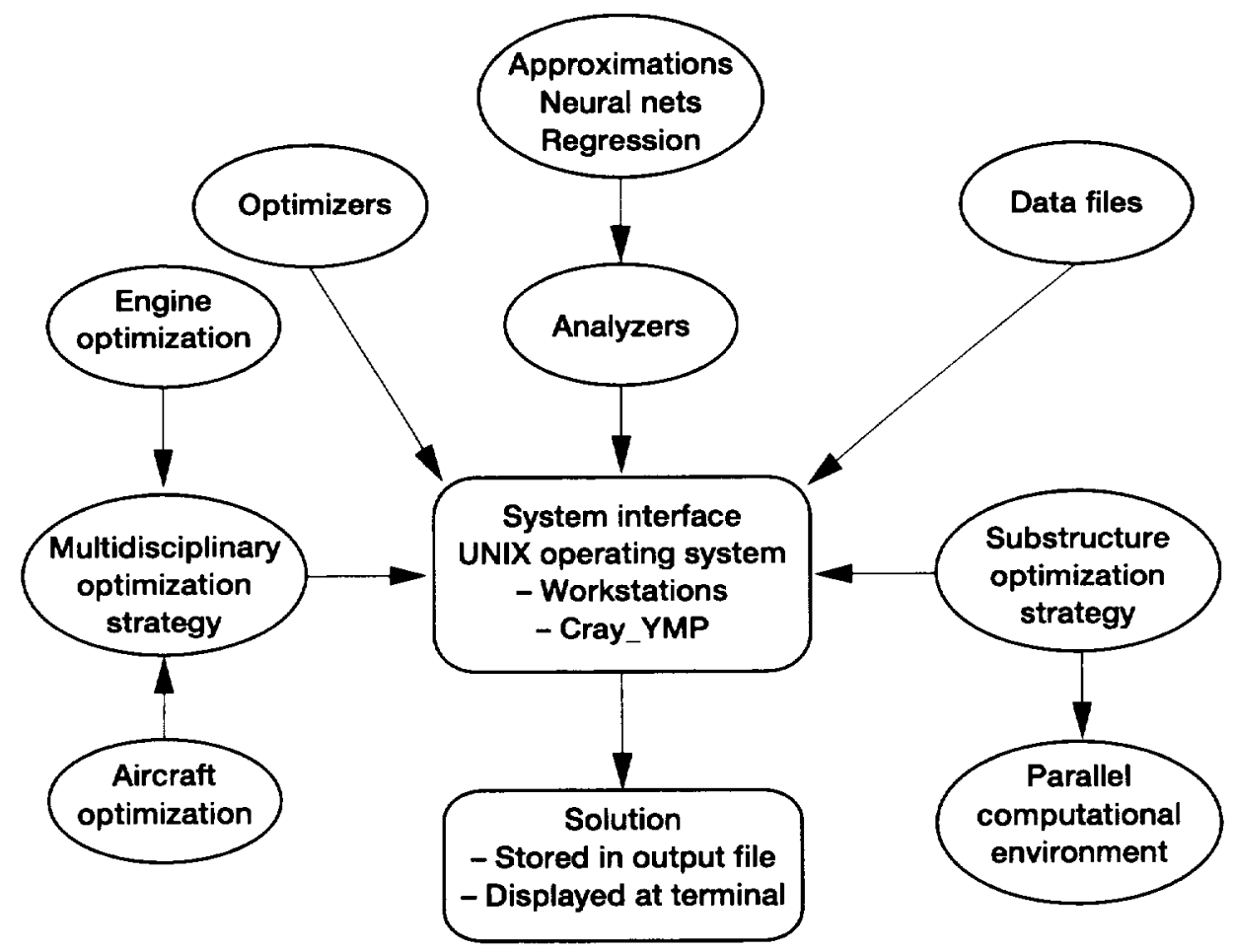

Fig. 1.-COMETBOARDS: General-purpose optimization engine for multidisciplinary design problems.

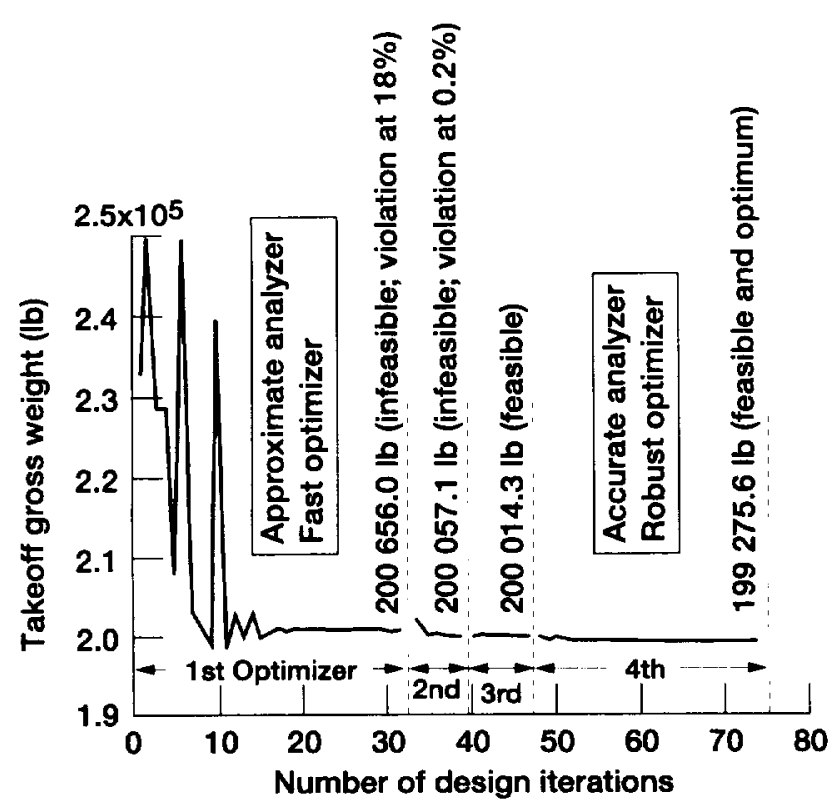

Fig. 2.-Cascade solution for a subsonic aircraft. 

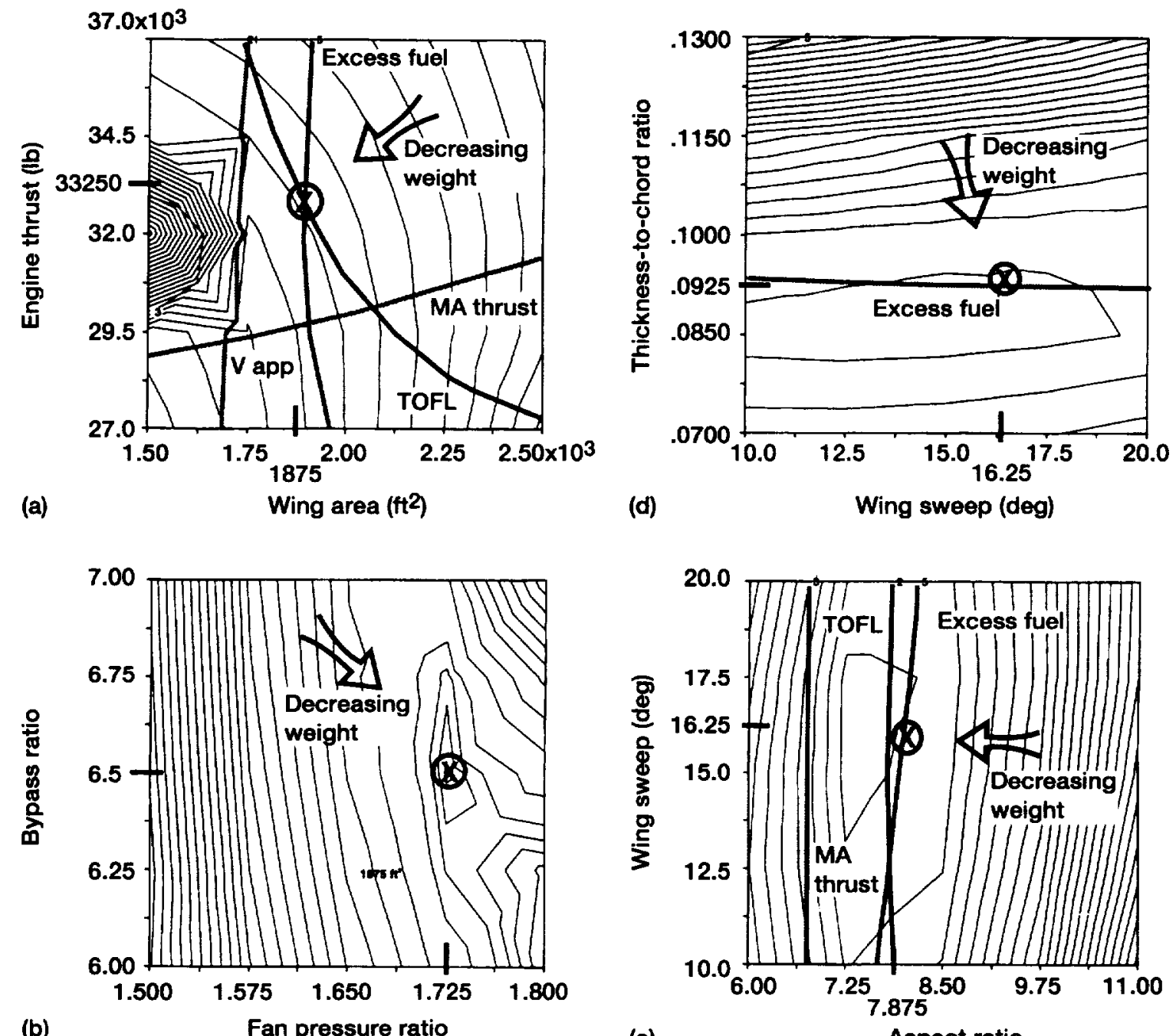

(b)

Fan pressure ratio

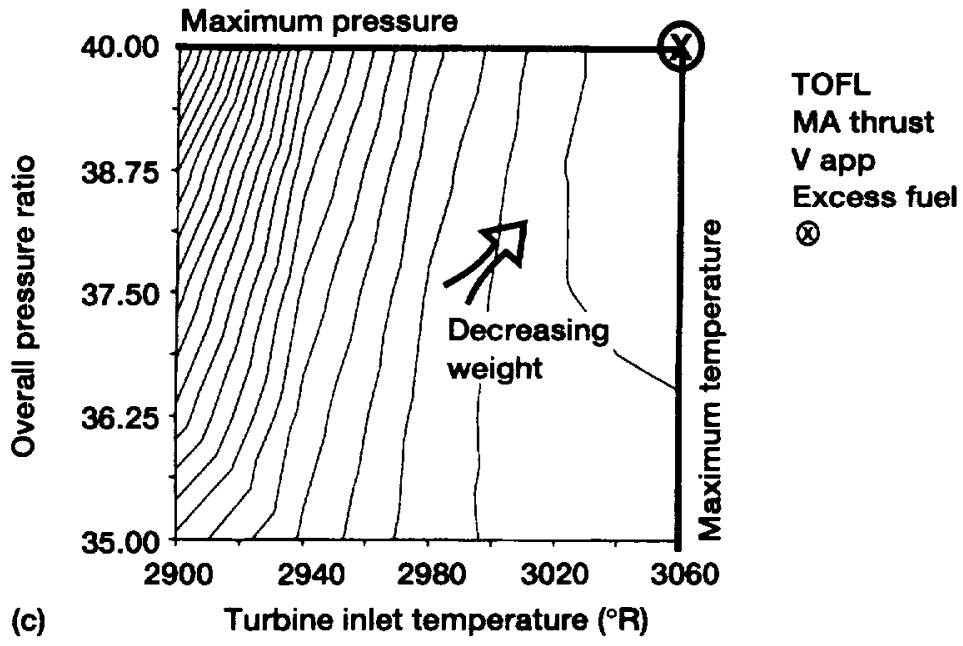
Takeoff field length
Missed approach climb thrust Approach velocity
Fuel storage available-fuel needed Optimum solution

Fig. 3.-Graphical verification of optimum design of subsonic aircraft. (a) Wing area versus engine thrust. (b) Fan-pressure ratio versus bypass ratio. (c) Turbine inlet temperature versus overall pressure ratio. (d) Wing sweep versus thickness-to-chord ratio. (e) Aspect ratio versus wing sweep. 


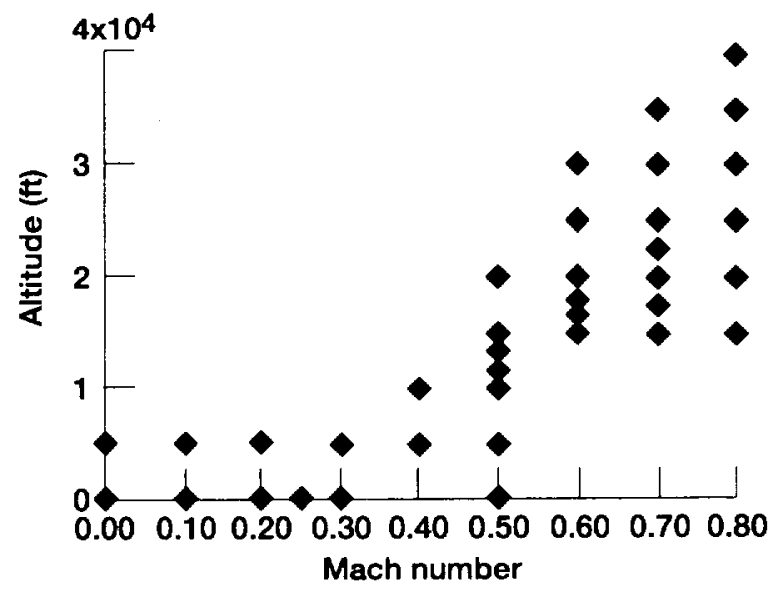

Fig. 4.-Forty-seven mission points for high-bypassratio-turbofan wave-rotor-topped engine.

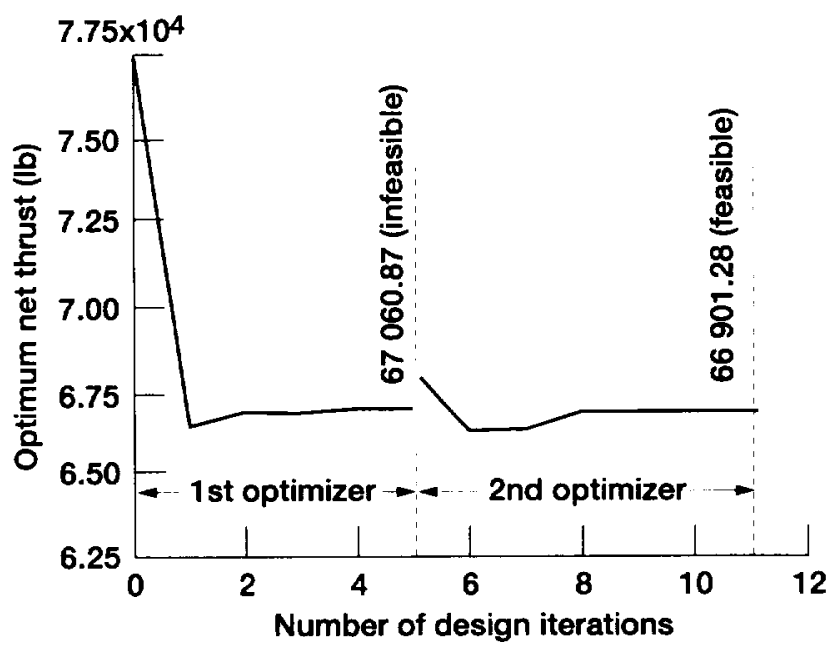

Fig. 5.-Cascade solution for a wave-rotor-topped subsonic engine. 
$\otimes$ Optimum solution

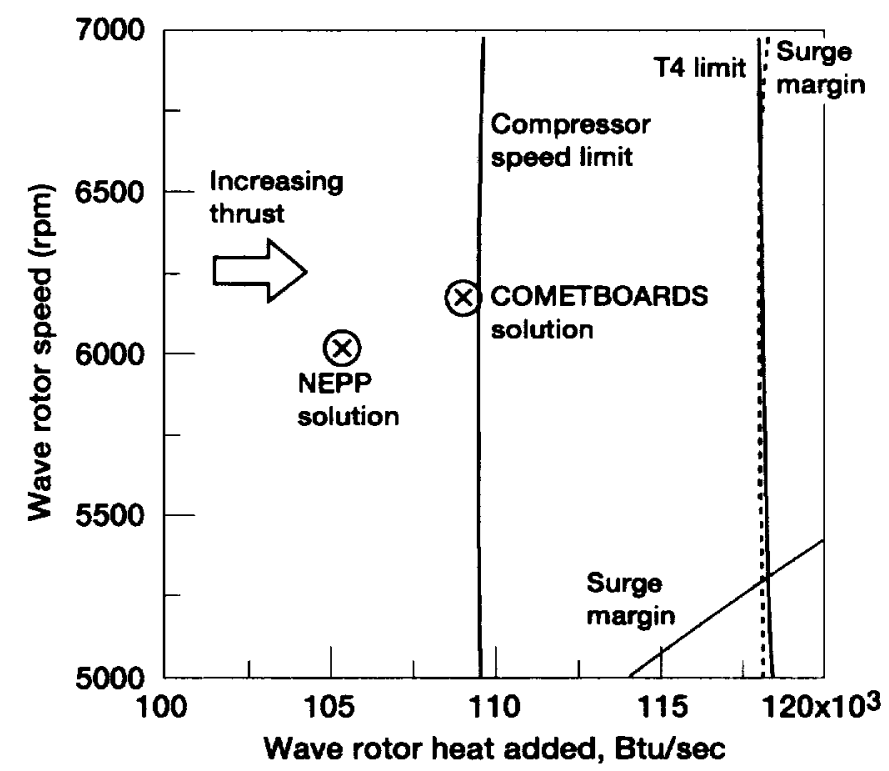

Fig. 6.-Graphical verification for subsonic wave rotor.

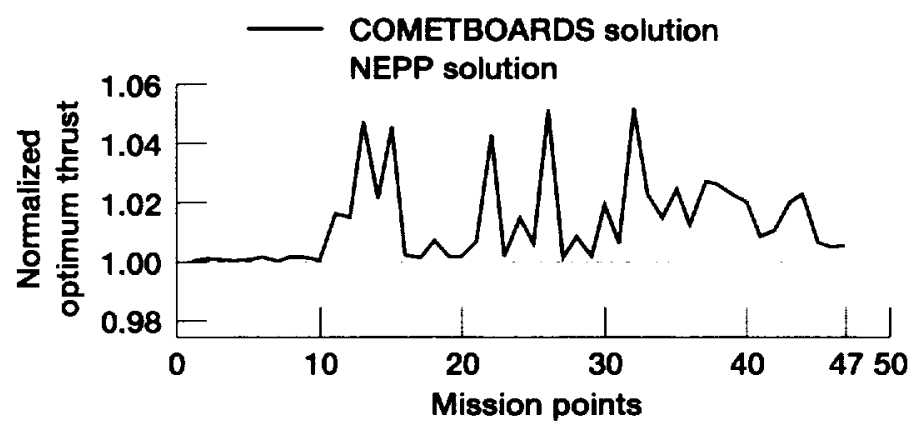

Fig. 7.-Value-added benefit in design of a 47-missionpoint, high-bypass-turbofan subsonic engine using a wave rotor. 

Public reporting burden for this collection of information is estimeted to werage 1 hour per response, including the time for reviewing instructions, searching existing data sources, gathering and maintaining the datn needed, and completing and reviewing the collection of information. Send comments regarding this burden estimate or any other aspect of this collection of information, including suggestions for reducing this burden, to Washington Headquarters Services, Drectorate for Information Operations and Reports. 1215 Jefferson Davis Highway. Suhe 1204. Arlington, VA 22202-4302, and to the Ollice of Management and Budgex. Papenwork Reduction Project (0704-0188). Weahingron, DC 20503.

\begin{tabular}{|l|l|l|}
\hline 1. AGENCY USE ONLY (Leave blank) & 2. REPORT DATE & 3. REPORT TYPE AND DATES COVEAED
\end{tabular}

\begin{tabular}{|l|l|l|l|}
\hline & July 1996 & Technical Memorandum \\
\hline
\end{tabular}

4. TITLE AND SUBTITLE

5. FUNDING NUMBEAS

Cascade Optimization Strategy for Aircraft and Air-Breathing Propulsion

System Concepts

6. AUTHOR(S)

WU-505-63-5B

Surya N. Patnaik, Thomas M. Lavelle, Dale A. Hopkins, and Rula M. Coroneos

7. PERFORMNG ORGANIZATION NAME(S) AND ADDRESS(ES)

8. PERFORMNG ORGANIZATION REPORT NUMBER

National Aeronautics and Space Administration

Lewis Research Center

Cleveland, Ohio 44135-3191

E-10346

9. SPONSORINGMONITORING AGENCY NAME(S) AND ADDRESS(ES)

10. SPONSORINGMONTTORING AGENCY REPORT NUMBER

National Aeronautics and Space Administration

Washington, D.C. 20546-0001

NASA TM-107278

AIAA-96-4145

11. SUPPLEMENTARY NOTES

Prepared for the Sixth Symposium on Multidisciplinary Analysis and Optimization cosponsored by AIAA, USAS, NASA, and ISSO, Bellevue, Washington, September 4-6, 1996. Surya N. Patnaik, Ohio Aenospace Institute, 22800 Cedar Point Road, Cleveland, Ohio 44142; Thomas M. Lavelle, Dale A. Hopkins, and Rula M. Coroneos, NASA Lewis Research Center. Responsible person, Thomas M. Lavelle, organization code 2430, (216) $977-7042$.

12a. DISTRIBUTIONAVALABILTTY STATEMENT

12b. DISTRIBUTION CODE

Unclassified - Unlimited

Subject Category 39

This publication is available from the NASA Center for AeroSpace Information, (301) 621-0390.

13. ABSTRACT (Maximum 200 words)

Design optimization for subsonic and supersonic aircraft and for air-breathing propulsion engine concepts has been accomplished by soft-coupling the Flight Optimization System (FLOPS) and the NASA Engine Performance Program analyzer (NEPP), to the NASA Lewis multidisciplinary optimization tool COMETBOARDS. Aircraft- and engine-design problems, with their associated constraints and design variables, were cast as nonlinear optimization problems with aircraft weight and engine thrust as the respective merit functions. Because of the diversity of constraint types and the overall distortion of the design space, the most reliable single optimization algorithm available in COMETBOARDS could not produce a satisfactory, feasible optimum solution. Some of COMETBOARDS' unique fearures, which include a cascade strategy, variable and constraint formulations, and scaling devised especially for difficult multidisciplinary applications, successfully optimized the performance of both aircraft and engines. The cascade method has two principal steps: In the first, the solution initiates from a user-specified design and optimizer; in the second, the optimum design obtained in the first step with some random perturbation is used to begin the next specified optimizer. The second step is repeated for a specified sequence of optimizers or until a successful solution of the problem is achieved. A successful solution should satisfy the specified convergence criteria and have several active constraints but no violated constraints. The cascade strategy available in the combined COMETBOARDS, FLOPS, and NEPP design tool converges to the same global optimum solution even when it starts from different design points. This reliable and robust design tool eliminates manual intervention in the design of aircraft and of air-breathing propulsion engines where it eases the cycle analysis procedures. The combined code is also much easier to use, which is an added benefit. This paper describes COMETBOARDS and its cascade strategy and illustrates the capability of the combined design tool through the optimization of a subsonic aircraft and a high-bypass-turbofan wave-rotor-topped engine.

14. SUBJECT TERMS

Air-breathing propulsion engine; Subsonic and supersonic aircraft; Design optimization

15. NUMBER OF PAGES 10

16. PRICE CODE

$\mathrm{A} 02$

\begin{tabular}{|c|c|c|c|}
\hline $\begin{array}{c}\text { 17. SECURTYY CLASSIFICATION } \\
\text { OF REPOAT } \\
\text { Unclassified }\end{array}$ & $\begin{array}{c}\text { 18. SECURTY CLASSIFICATION } \\
\text { OF THIS PAGE } \\
\text { Unclassified }\end{array}$ & $\begin{array}{c}\text { 19. SECURITY CLASSIFICATION } \\
\text { OF ABSTRACT } \\
\text { Unclassified }\end{array}$ \\
\hline
\end{tabular}

NSN 7540-01-280-5500

Standard Form 298 (Rev. 2-89) Prescribed by ANSI Sid. Z39-18 298-102 


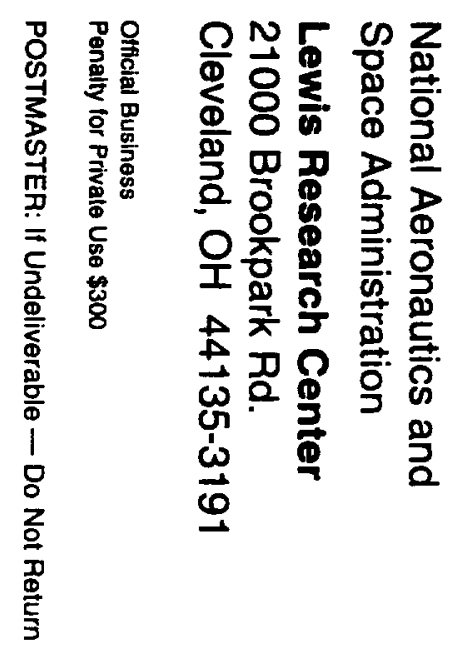

